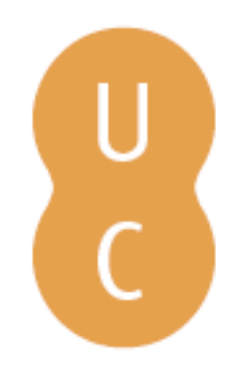

\title{
nombalina
}

\section{A avaliação de grandes traumatizados e a atribuição da terceira pessoa}

Autor(es): $\quad$ Magalhães, Teresa; Vieira, Duarte Nuno

Publicado por: Imprensa da Universidade de Coimbra

URL

persistente: $\quad$ URI:http://hdl.handle.net/10316.2/32129

DOI: $\quad$ DOI:http://dx.doi.org/10.14195/978-989-26-0400-8_7

Accessed : $\quad$ 26-Apr-2023 05:36:23

A navegação consulta e descarregamento dos títulos inseridos nas Bibliotecas Digitais UC Digitalis, UC Pombalina e UC Impactum, pressupõem a aceitação plena e sem reservas dos Termos e Condições de Uso destas Bibliotecas Digitais, disponíveis em https://digitalis.uc.pt/pt-pt/termos.

Conforme exposto nos referidos Termos e Condições de Uso, o descarregamento de títulos de acesso restrito requer uma licença válida de autorização devendo o utilizador aceder ao(s) documento(s) a partir de um endereço de IP da instituição detentora da supramencionada licença.

Ao utilizador é apenas permitido o descarregamento para uso pessoal, pelo que o emprego do(s) título(s) descarregado(s) para outro fim, designadamente comercial, carece de autorização do respetivo autor ou editor da obra.

Na medida em que todas as obras da UC Digitalis se encontram protegidas pelo Código do Direito de Autor e Direitos Conexos e demais legislação aplicável, toda a cópia, parcial ou total, deste documento, nos casos em que é legalmente admitida, deverá conter ou fazer-se acompanhar por este aviso. 


\section{Aspectos práticos da avaliação do dano corporal em Direito Civil}

Coordenação

Duarte Nuno Vieira

José Alvarez Quintero

Biblioteca Seguros 
(Página deixada propositadamente em branco) 


\title{
VII - A Avaliação de Grandes Traumatizados e a Atribuição da Terceira Pessoa
}

\author{
Teresa Magalhães \\ Duarte Nuno Vieira
}

\section{INTRODUÇÃO}

A problemática dos traumatizados graves, nomeadamente no que se refere à satisfação de algumas das suas necessidades com base em apoios tecnológicos ou de terceira pessoa, pouco ou nenhum interesse suscitou durante décadas sucessivas junto de todos quantos estão envolvidos na avaliação e reparação de danos corporais. Os destinatários do relatório pericial (juizes, seguradoras, advogados e até as próprias vítimas) contentavam-se, frequentemente, com a simples indicação pelo perito médico sobre se eram indispensáveis ajudas, qual o seu tipo e qual a duração da necessidade, sendo na maioria das vezes as fundamentações exaradas nos relatórios o resultado da rotina pericial então em uso, ou seja, a mera transcrição das queixas da vítima, e não o resultado ponderado de uma observação pericial adequada e de uma análise crítica do caso. Relativamente a estes aspectos, os peritos procediam pois, e indiscutivelmente, de forma mais ou menos estereotipada, num consenso que se caracterizava por aquilo que se tem designado por "facilitismo pericial".

Mas desde os finais do século XX vem-se verificando um interesse crescente pelas vítimas de traumatismos graves. Aumento que decorre muito particularmente da influência de três factores. Por um lado, do incremento do número de sinistrados com sequelas graves, face à melhoria significativa da intervenção médica inicial e dos progressos das técnicas terapêuticas, que vêm permitindo a sobrevida de um cada vez maior número de vítimas em eventos que outrora conduziriam, inevitavelmente, a desenlaces fatais. Por outro, a pressão de advogados e médicos especialistas que, de forma progressiva e crescente, vão estando mais sensibilizados e atentos relativamente à importância destas ajudas, particularmente nos casos dos traumatizados vértebro-medulares e crânio-encefálicos graves, situações que representam as categorias de vítimas nas quais mais frequentemente se verificam handicaps 
graves. Por outro lado ainda, o facto de, progressivamente, vir ganhando força a ideia da necessidade de reparar diferentemente os danos graves; de reparar ajudando e não apenas pagando. Esta ideia, embora ainda longe de recolher apoio unânime, afigura-se indiscutivelmente mais respeitadora da pessoa na sua dignidade, no seu direito à integração social e à não exclusão, na sua própria qualidade de vida.

O dano corporal consiste, na maioria das vezes, num prejuizo primariamente biológico (no corpo) que se pode traduzir por perturbações a nível das capacidades, das situações de vida e da subjectividade da vítima. Está pois em causa não apenas o dano no corpo mas, antes, um dano nos diversos níveis que integram a pessoa.

Este conceito, assim definido, é particularmente importante no caso dos traumatizados graves, uma vez que na sequência do dano no corpo resultam consequências que vêm alterar profunda e permanentemente a vida diária, familiar, social, de lazer, de formação e(ou) profissional daquelas pessoas. Mais adequado seria, pois, eventualmente, referirmo-nos a danos na pessoa e não a danos corporais, sendo todavia certo que esta designação tem entre nós (e em muitos outros países) uma tradição e um peso tão significativo que é difícil fugir do seu uso. Alguns países conseguiram todavia abraçar outras designações que vão mais no sentido assinalado, como, por exemplo Itália, onde se generalizou a expressão dano biológico.

Nas situações de grandes traumatizados, o objectivo da avaliação e reparação dos danos surge, naturalmente, associado ao objectivo da reintegração e reinserção das vítimas, importando por isso que este conceito de dano corporal/dano na pessoa seja sempre analisado do ponto de vista das suas situações concretas de vida. Tal implica compreender o dano a partir das seguintes noções essenciais (Didier J-P e col, 1988):

a) o importante não é o que se perdeu, mas o que resta (capacidade restante);

b) as consequências para a vida real (sequelas situacionais ou handicaps) são uma situação relativa que depende de factores pessoais mas, também, de factores do meio, pelo que poderá ser possível minorá-las alterando o meio;

c) o curso patológico é uma contínua interacção com o meio, onde cada etapa depende da precedente e explica a seguinte;

d) a qualidade de vida depende do correcto aproveitamento das capacidades restantes.

Assim, a referência constante ao meio e ao quadro de vida da pessoa constitui uma passagem obrigatória para a avaliação dos danos na pessoa com handicap grave. A descrição concreta dos actos, gestos e movimentos, tornados dificeis e parcial ou totalmente impossiveis em consequência do evento traumático, permitirá definir os prejuízos na perspectiva da perturbação da autonomia e propor, concretamente, as intervenções necessárias sobre o meio individual susceptiveis de reduzir esta limitação (pessoas próximas, habitação, local de educação, de trabalho ou recreativo, meios de comunicação, de transporte ou de acesso a um conjunto de serviços adaptados às suas necessidades, por exemplo). Um estudo deste tipo obriga, evidentemente, à realização de uma perícia multidisciplinar, constituindo parte fundamental da avaliação das vítimas com handicap grave.

\section{CONCEITO DE HANDICAP GRAVE}

Partindo da noção de handicap, começou a desenvolver-se nos anos 60 uma corrente doutrinária - designada por "Handicapologia" - que veio 
revolucionar (e também humanizar) a forma de encarar as consequências das doenças e dos traumatismos, influenciando igualmente a perspectiva médico-legal sobre estes casos.

o handicap, ou melhor, as situações de handicap, traduzem-se pela dificuldade da pessoa realizar os seus gestos habituais da vida quotidiana, no contexto da sua idade, sexo e identidade sociocultural. Isto em consequência, por um lado, de sequelas a nível orgânico e funcional e, por outro, de obstáculos devidos a factores do meio (conjunto das dimensões sociais, culturais e ecológicas que determinam a organização e o contexto de uma sociedade).

Assim, o handicap - muitas vezes designado em termos médico-legais por sequelas situacionais -, não é uma constante mas, antes, uma variável relativa e sempre em evolução, não sendo possivel pensar no seu estudo sem o perspectivar na área do indivíduo com as suas capacidades e os seus limites, e na área das situações sociais (meio) com que esse mesmo indivíduo se confronta.

Esta noção põe, pois, em evidência, a importância do meio na produção do handicap, fazendo realçar uma certa oposição entre a concepção tradicional da avaliação e reparação dos danos (cujo montante depende, sobretudo, do grau de incapacidade constatado no momento da decisão), e uma reparação que deverá ter também em conta os factores pessoais e do meio que implicam a ideia de situação de handicap, favorecendo, acima de tudo, a readaptação e reintegração que os progressos tecnológicos, da medicina e da técnica tornam cada vez mais eficazes.

O handicap será considerado grave nos casos em que a pessoa apresenta sequelas a nível orgânico e funcional, cuja intensidade a impede de realizar com autonomia as suas actividades da vida diária.

A tónica do estudo destes casos será, assim, a questão da autonomia, constantemente associada às questões da dependência. 0 fundamental será perceber os tipos de interacção da pessoa com o seu meio, tendo em vista estudar o seu grau de autonomia e independência de modo a que, através da satisfação das suas necessidades em termos tecnológicos (ajudas técnicas, adaptações de espaços, etc.) se incremente, o mais possivel, a sua autonomia, a qual se perderá quando não for de todo possivel evitar o recurso a ajuda de terceira pessoa.

De uma forma geral, as pessoas com handicaps graves são aquelas que apresentam estados vegetativos persistentes, perturbações cognitivo-afectivas graves, plegias, grandes amputações, graves sequelas de queimaduras ou de politraumatismos, ou amaurose.

\section{OBJECTIVOS DA AVALIAÇÃO E REPARAÇÃO DOS TRAUMATIZADOS GRAVES}

A avaliação dos danos na pessoa, no âmbito do Direito Civil, visa, de uma forma genérica, orientar em termos técnicos e científicos, a reparação desses danos, permitindo que essa reparação seja justa e adequada às reais necessidades das vítimas. Tal está de acordo com dois princípios fundamentais contemplados nos diversos ordenamentos jurídicos dos países da União Europeia: todos gozamos plenamente dos mesmos direitos e, no caso de dano corporal, a situação deve ser reposta o mais próximo possivel daquela que existiria se o evento não tivesse tido lugar 1 . 
Mas no que se refere aos handicaps graves, as actuais políticas de proteç̧ão e promoção dos direitos humanos e questões de ordem económica, atento o peso socioeconómico das sequelas pós-traumáticas graves, obrigam a equacionar constantemente a questão da melhor reabilitação da vítima, tendo em vista o melhor e rápido possível retorno à vida activa e, se exequível, a uma actividade produtiva.

Assim, o Direito prevê meios de compensação e de reparação que têm como objectivos, entre outros, a reinserção familiar, social e profissional das vítimas. Tal passa por avaliar e reparar estas pessoas de uma forma não estandardizada, mas adaptada às particularidades do seu estado, de modo a procurar repor a sua situação de vida tal como esta era antes do evento ou, pelo menos, o mais próximo possível dela.

Desta forma, o dano indemnizável deverá certamente residir muito menos nas sequelas anátomo-fisiológicas do que nas suas múltiplas consequências no plano da vida quotidiana, da vida afectiva, familiar e da vida profissional ou de formação. Note-se, que os actos essenciais da vida não se limitam à satisfação das necessidades fisiológicas, ao vestir-se e ao lavar-se; existem indiscutivelmente muitas outras aspirações, como por exemplo a possibilidade de comunicar, de obter conhecimentos ou desenvolver passatempos, aspirações estas que devem ser, também elas, tidas em consideração. Importará, pois, ter em conta o "bem-estar físico, mental e social", a reintegração familiar, social e profissional, bem como a qualidade e o projecto de vida destas pessoas.

A satisfação deste objectivo passará por uma avaliação médico-legal detalhada e personalizada da globalidade dos danos e por uma reparação concreta desses mesmos danos. Trata-se de situação distinta da que verifica com as sequelas ligeiras, sem repercussões patrimoniais permanentes e no quadro de vida da vítima, em que a indemnização constituirá essencialmente uma compensação pelo dano sofrido, a qual poderá ser determinada de forma abstracta, com recurso a tabelas médicas e de indemnização, que se aplicam igualmente a todos os casos.

\section{METOdologias de AVALIAÇÃo. UMA AVALIAÇÃO MULTIDISCIPLINAR}

Tendo em conta o atrás referido, a avaliação médico-legal do handicap grave implicará uma metodologia que passa pela avaliação pericial tradicional, sendo a vítima examinada na perspectiva da avaliação tridimensional do dano (corpo, funções e situações), o que permitirá descrever o dano, definir a data de consolidação médico-legal das lesões e ponderar os diversos parâmetros do dano (temporários e permanentes) valorizáveis em direito civil. Deve sublinhar-se a este respeito, que muitas correntes doutrinárias insistem na desadequação da quantificação da incapacidade permanente geral nestas situações, por a "hiper-valorização" deste parâmetro de dano pela entidade reparadora poder desvirtuar aquilo que de importante está efectivamente em causa, e sendo certo que as quantificações numéricas (já por si de alguma forma fluidas) fazem menos sentido nas grandes incapacidades.

Mas a esta avaliação acrescerá uma avaliação (funcional e situacional) realizada por uma equipa multidisciplinar (que poderá incluir por exemplo, médico fisiatra, terapeuta ocupacional e da fala, neuro-psicólogo, arquitecto, especialista em domótica e assistente social), a qual, atendendo à estabilização das sequelas, definirá as diversas necessidades da vítima em termos da sua reabilitação e reinserção, tendo como objectivo primordial 
promover a sua melhor autonomia, mesmo que tal autonomia seja conseguida à custa de diversas dependências, como sejam as ajudas medicamentosas, técnicas, animais ou adaptações.

Idealmente, preconiza-se a realização de uma primeira perícia ainda antes de a vítima ter alta do serviço hospitalar onde se encontra internada para que, com base na possibilidade de reparar a título de provisão, possa desde logo começar a usufruir não só das ajudas técnicas como das necessárias adaptações do domicílio e de ajuda de terceira(s) pessoa(s), de modo a que o seu primeiro confronto com o mundo real seja o menos doloroso possivel e se facilite a sua mais pronta reintegração. Outras perícias de "follow-up" deveriam nestes casos ser feitas, permitindo ajustar todas as necessidades da vítima, as quais, se vão forçosamente alterando com o evoluir do tempo. Este tipo de avaliação/reparação corresponde a um desejo legítimo, mas, infelizmente, nem sempre realizável no contexto da reparação do dano, uma vez que para que a vítima disponha de todas as ajudas técnicas desejáveis e de um domicílio adaptado, é frequentemente necessário que já tenha sido indemnizada, dado que as provisões atribuídas pela seguradora do responsável são normalmente insuficientes para o efeito. Idealmente, a última perícia deveria ser realizada quando se verificar não só a consolidação funcional mas, também, a chamada consolidação situacional, ou seja, quando todas as ajudas técnicas e adaptações necessárias tiverem sido concretizadas e a pessoa estiver adaptada a elas, tendo encontrado o seu novo equilíbrio. Nesta altura deverá ser ouvida não apenas a vítima mas, também, a sua família e as pessoas que a apoiam (médicos e paramédicos), para um melhor conhecimento da situação concreta.

\section{DESCRIÇÃO TRIDIMENSIONAL DOS DANOS NA PESSOA E VALORIZAÇÃO DOS DIVERSOS PARÂMETROS DE DANO}

Os métodos de avaliação do dano corporal têm evoluído pouco, sendo a taxa de incapacidade permanente (de zero a cem), até agora, a forma mais frequentemente utilizada para a avaliação e reparação dos danos permanentes em termos da afectação da integridade física e psíquica. No entanto, este método usualmente assente em tabelas, é incapaz de responder à evolução das necessidades em termos de reparação do handicap, pois as consequências do dano são, nestes casos, particularmente complexas, alterando-se por completo todo o esquema de vida da pessoa. Uma tal situação não é, naturalmente, passivel de ser traduzida por uma percentagem.

Um aspecto importante da avaliação médico-legal é a determinação do momento em que sequelas se consideram definitivas e, portanto, passiveis de serem valoradas e reparadas. No caso dos handicaps graves, como já referido, importa atender à estabilização médico-legal das sequelas, que será o momento em que a pessoa se reintegrou o melhor possivel, face às suas sequelas e ao meio que a rodeia, não sendo de prever grandes mudanças no seu quadro de vida. A observação corrente mostra, no entanto, que muitas das sequelas não podem ser, a priori, consideradas estabilizadas e definitivas numa data específica, dado que os progressos da ciência médica (nomeadamente, das técnicas cirúrgicas e de reeducação funcional) e da tecnologia, criam, cada dia, mais esperanças e possibilidades de melhoria, não permitindo que se considere actualmente definitivo um resultado terapêutico adquirido em determinado momento. Sabemos também que nenhuma situação é totalmente 
permanente e que a própria envolvência situacional se poderá alterar (por razões diversas) ao longo dos anos. Por isso, nestes casos, o ideal seria a modalidade de reparação em renda, que poderia permitir ir ajustando, ao longo da vida da vítima, as suas novas necessidades e fazer o melhor aproveitamento da evolução tecnológica. Mas existem também algumas desvantagens óbvias neste procedimento.

Outro aspecto fundamental da avaliação médico-legal tem a ver com a descrição dos danos do ponto de vista tridimensional: sequelas corporais, funcionais e situacionais.

Esta avaliação tridimensional foi pela primeira vez preconizada por Nagi, em 1965. Entretanto, foi abraçada pela OMS que, através de Philips Wood a apresentou em 1980 na sua International Classification of Impairments, Disabilities and Handicaps - ICIDH-1. Porque esta classificação apresentava algumas limitações na definição clara dos aspectos que integravam cada um dos três níveis, outros investigadores desenvolveram propostas paralelas, como o caso de C. Hamonet (Handicapomètre DAC - 1980) ou de P. Fougeyrollas (Classificação do Comité do Quebec e Sociedade Canadiana da ICIDH - 1987), propostas estas que viriam a ser consideradas pela OMS. Também na perspectiva médico-legal esta ideia mereceu acolhimento, tendo-se desenvolvido, em conjunto com os dois últimos autores citados, o Inventário de Avaliação do Dano Corporal (IADC), apresentado em 1997 e que se baseia numa lógica absolutamente sobreponível à última versão (2001) da International Classification of Functioning, Disability and Health da OMS (ICIDH-2), tendo como vantagem o facto de se tratar de um instrumento validado.

O IADC propõe três níveis de avaliação (corpo, funções e situações), niveis estes que constituem a base da actual estrutura do capítulo do "Estado Actual" de todos os relatórios de avaliação do dano corporal pós-traumático, a nível do Instituto Nacional de Medicina Legal, I.P. Esta avaliação tridimensional permite uma aproximação mais efectiva à globalidade e realidade do dano, a sua descrição mais orientada, pormenorizada e sistematizada e tem como perspectiva a reparação do dano em termos concretos ou mais próxima daquela que seria a reparação integral. No caso dos traumatizados graves pode recorrer-se à aplicação do IADC, propriamente dito, o qual permite a quantificação do dano de forma global e personalizada, em 5 graus claramente discriminados de acordo com o grau de autonomia e independência da vítima.

Na sequência da descrição tridimensional do dano, poderão ser valorizados os diversos parâmetros de dano, temporários (incapacidades temporárias gerais e profissionais e quantum doloris) e permanentes (incapacidade permanente geral, dano estético, prejuizo sexual, prejuízo de afirmação pessoal e rebate profissional). No relatório médico deverá, ainda, ser feita menção às diversas dependências/necessidades apresentadas pela vítima, recorrendo-se, idealmente, a equipas de profissionais habilitadas que, no terreno, poderão estudar com maior acuidade estes aspectos.

\section{A DESCRIÇÃO DAS NECESSIDADES}

O estudo do handicap, como parte fundamental do dano corporal, permite objectivar as necessidades das pessoas, sendo esta uma das principais justificações para a sua avaliação. A descrição concreta dos actos, gestos e movimentos tornados dificeis e parcial ou totalmente impossiveis em consequência do traumatismo, permite definir os prejuízos em termos de 
autonomia e indicar as intervenções sobre o meio individual, precisando os meios técnicos e humanos necessários para limitar ou reduzir o dano corporal e a perda de autonomia: adaptações do domicílio (das casas de banho, dos meios de acesso, etc.), ajudas técnicas (ortóteses, lombostatos, sapatos ortopédicos, aparelhagem urinária, cadeira de rodas, camas adaptadas, etc.), veículos adaptados (para ser conduzidos pelo próprio ou por terceiros, compreendendo-se aqui a necessidade de uma carta de condução especial), adaptações necessárias ao exercício de uma actividade profissional (no domicílio ou na empresa) e ajuda humana ou assistência (assistência técnica por pessoal médico e paramédico ou pela família, vizinhos ou amigos).

Importará, ainda, neste momento da avaliação do handicap, descrever não só o custo destas ajudas e intervenções, como caracterizá-las e identificar a duração (período de renovação) das ajudas técnicas.

As dependências podem ser temporárias ou permanentes, sendo as permanentes mais frequentemente valorizadas enquanto tal. Como já referido, podem ser relativas a diversos tipos de necessidades: medicamentosas, animais, tratamentos clínicos, ajudas técnicas, adaptações (domicílio, local de trabalho, viatura), ou ajuda de terceira pessoa.

\subsection{AJUDAS MEDICAMENTOSAS E TRATAMENTOS MÉDICOS REGULARES}

As ajudas medicamentosas referem-se à necessidade permanente de recurso a medicação regular (ex: analgésicos, antiespasmódicos ou antiepilépticos), sem a qual a vítima não conseguirá ultrapassar as suas dificuldades em termos funcionais e nas situações da vida diária.

A dependência de tratamentos clínicos regu- lares corresponde à necessidade de recurso regular a cuidados de saúde para evitar o retrocesso ou o agravamento das sequelas (ex.: fisioterapia).

\subsection{AJUDAS TÉCNICAS, DE ANIMAIS E ADAPTAÇÕES}

A dependência de ajudas técnicas refere-se à necessidade permanente de recurso a tecnologia para prevenir, compensar, atenuar ou neutralizar o dano corporal (do ponto de vista anatómico, funcional e situacional), tendo em vista a obtenção de autonomia e independência nas actividades da vida diária. Podem tratar-se de ajudas técnicas lesionais, funcionais ou situacionais. As ajudas a que mais frequentemente se recorre, nos casos dos traumatizados graves são as ajudas para as deslocações interiores e de proximidade, como é o caso de cadeira de rodas, havendo, no entanto, que pensar noutro tipo de ajudas, como para deslocações a grandes distâncias, ajudas de comunicação e ajudas de conforto e acessibilidade.

Em alguns casos estas ajudas podem ser substituidas ou contempladas por ajudas animais, como o caso de cães especificamente treinados para o efeito e particularmente usados nas situações de amaurose e em alguns casos de paraplegia ou tetraplegia.

Pode, ainda, verificar-se necessidade de adaptação do domicílio ou do local de trabalho, ou seja, a necessidade de recurso à tecnologia a nível arquitectónico ou de mobiliário e equipamentos, no sentido de permitir a realização de determinadas actividades diárias a pessoas que, de outra maneira, o não conseguiriam fazer, com o risco de perda da sua autonomia. As adaptações mais frequentes verificam-se a nivel da acessibilidade, equipamento sanitário e cozinha, devendo contudo ser pensadas outras soluções em termos da domótica e controlo do ambiente, soluções estas 
que possam assegurar, em certa medida, a segurança e prevenção de riscos (incêndio por exemplo através de detectores), a assistência em casos de perigo (televigilância), as actividades de laser, o conforto (abertura e fecho de portas, janelas, interruptores, etc.) e a comunicação com o exterior.

Estes dispositivos poderão ajudar certas pessoas a melhorar a sua autonomia e reduzir a necessidade de ajuda de terceira pessoa, solução esta muito mais consentânea com os reais interesses das vítimas e com a actual realidade sócio-cultural. De facto, na actual sociedade, perspectiva-se que cada vez mais as pessoas apoiadas por esta tecnologia, apenas tenham de recorrer a serviços auxiliares de vida organizados de forma a assegurar prestações de duração limitada mas em momentos precisos do dia, ainda que sendo capazes de fazer face a toda a situação não prevista ou urgente.

\subsection{DEPENDÊNCIA DE TERCEIRA PESSOA}

A dependência de terceira pessoa corresponde ao conjunto de meios humanos susceptíveis de permitirem às pessoas com handicaps graves e que se encontram dependentes, realizarem os gestos que se tornaram impossíveis na realização de uma determinada função ou situação de vida diária. Refere-se a todos os tipos de ajudas humanas, incluindo as clínicas.

A redução ou perda de autonomia associada a esta dependência, não é nem proporcional, nem mesmo paralela, à afectação da integridade física e ao valor da incapacidade permanente geral, dependendo de outros aspectos relacionados, muito particularmente, com factores pessoais e do meio. Nestes casos, serão mais relevantes os factores pessoais já que os do meio podem, e devem, ser alterados.

É por isso que o estudo final sobre a neces- sidade de terceira pessoa não pode ser jamais um procedimento isolado de um contexto, sendo indispensável que já se tenha verificado não só a consolidação funcional como a situacional, que o sinistrado tenha regressado ao domicílio que ocupará definitivamente e esteja instalado em condições de vida presumivelmente duráveis, que as eventuais adaptações no domicílio tenham sido concluídas, que as ajudas técnicas possiveis tenham sido concretizadas e que a vítima esteja já incorporada num novo projecto de vida.

Idealmente, esta avaliação será multidisciplinar e realizada no meio de vida da vítima (domicílio e local de trabalho), após uma avaliação médica (análise das sequelas orgânicas, funcionais e, muito particularmente, situacionais) e uma avaliação, por técnicos especializados, quanto às necessidades em termos de ajudas técnicas e de adaptação do domicílio. A avaliação da necessidade de terceira pessoa será sempre feita considerando as capacidades restantes e a autonomia da vítima, com e sem ajudas técnicas.

Para apoiar este tipo de avaliação, diferentes questionários têm sido desenvolvidos com o objectivo de permitirem apreciar a extensão da necessidade de assistência. A maioria deles envolve os grandes sectores de actividades fundamentais da vida corrente, repartidos pelas seguintes rubricas: actos da vida corrente; actos da vida doméstica; actos correntes fora do domicílio; actividades de cuidados de saúde; actos da vida familiar e social; actividades de lazer; actos da vida profissional. A vantagem destes instrumentos é a sua facilidade de aplicação e uma certa uniformização na avaliação, sobretudo para os avaliadores pouco familiarizados com este tipo de perícia, mas tal não deve dispensar uma aproximação personalizada ao paciente, às suas reais necessidades, nem o enunciar das diversas 
necessidades identificadas. Entre estes instrumentos podem assinalar-se, a título de exemplo, os seguintes: Escala ELISA (Estimation of Loss of Independence for Daily Activities) de Brusselmans, 1992; Grelha do FAT (Fonds des Accidents du Travail); ficha de avaliação de Rogier; Escala de Lucas e Stehman (1993); método do relógio; tabela espanhola, etc.

Em termos de missão pericial, devem, pois, ser atendidos nestes casos os seguintes aspectos:

1. A vítima deve idealmente ser examinada nas suas condições de vida definitiva, uma vez concretizadas todas as adaptações do domicílio e facultados todos os aparelhos, ajudas técnicas e controlos de ambiente, que devem ser descritos justificando a sua razão de ser.

2. Deve descrever-se o desenvolvimento de um dia de vida da vítima (nas suas 24 horas diárias) indicando os gestos e actos que ela não pode realizar, devendo para tanto procurar ouvir-se não só a vítima como os seus familiares e o pessoal técnico que a assiste;

3. O perito deverá esclarecer sobre a necessidade de ajuda de uma terceira pessoa e se essa necessidade é temporária ou definitiva, justificando;

4. Deve caracterizar essa terceira pessoa (ou pessoas) quanto ao tipo de ajuda, indicando:

a) Número de terceiras pessoas.

b) Categoria(s) sócio-profissional(ais) necessária(s) (técnica ou não).

c) Qualificações e funções: as qualificações podem ser muito variáveis segundo o tipo de tarefas atribuídas, podendo ir desde um auxiliar de vida/dama de companhia/empregada doméstica ou mesmo membros da família, a pessoal mais especializado como auxiliar de enfermeiro, paramédico, enfermeiro, fisiatra ou assistente social. d) Grau e tipo de ajuda (passiva ou activa)2: - substituição (total): sempre que a pessoa estiver de todo incapacitada para realizar qualquer gesto relativo aos cuidados pessoais e actividades da vida diária;

- de complemento ou assistência (parcial): nos casos em que a pessoa estiver dependente mas conseguir, ainda assim, realizar alguns gestos, os quais, apesar de tudo, não são suficientes para cumprir determinada situação, necessitando de complemento de terceiros;

- de incitação ou estimulação (parcial): visa ajudar a reintegração da pessoa, a elaboração de novas estratégias que conduzam a actividades autónomas; muitas vezes é uma atribuição de curta ou média duração;

- de vigilância (passiva): tem lugar apenas se os aspectos em causa não forem passíveis de substituição por um sistema de assistência técnica; trata-se, em geral, de pessoa sem qualificação particular, para supervisão das actividades ou para vigilância e segurança.

e) Tipo de actividades que as intervenções visam suportar: em função da natureza do handicap as necessidades de ajuda podem envolver as actividades seguintes: actos da vida corrente diária (levantar-se, deitar-se, deslocar-se, tratar da higiene pessoal, vestir-se, alimentar-se, etc.); actos da vida doméstica (preparar as refeições, pôr a mesa, lavar a louça, fazer a cama); actos correntes fora do domicílio (compras, deslocar-se individualmente e em transportes públicos);

\footnotetext{
2 Esta classificação é equivalente à classificação espanhola para acidentes de viação: Completa (69-72 pontos), Grave (44-69 pontos), Moderada (29-44 pontos) e Ligeira (15-29 pontos) - Ley 34/2003, de 4/11 (B.O.E. de 5/11/2003)
} 
actividades decorrentes dos cuidados de saúde (toma de medicamentos, tratamentos anti-escaras, oxigenoterapia, idas ao médico); actos da vida familiar e social (telefonar, escrever, tarefas administrativas ou de gestão do orçamento); actos de lazer. Deverão indicar-se para esta gama de actividades, quais as tarefas concretas que a ajuda visa realizar (ex: vigilância de parâmetros vitais, administração de terapêutica, higiene, vestuário, alimentação, etc.).

f) Local das intervenções (domicílio, exterior ou estabelecimento adaptado, etc.).

و) Duração e frequência (horário) das intervenções (número de horas por dia): a necessidade de assistência pode, segundo os casos, variar no tempo e em frequência, pelo que a indemnização relativa a esta necessidade deve prever reservas ou modalidades que visem tais variações de necessidade no decurso do tempo.

A necessidade de assistência de terceira pessoa é um dano que pode variar no tempo segundo as circunstâncias de vida da vítima.

Cada um destes casos deve ser entendido como particular. Existem, no entanto, quatro categorias de vítimas que justificam, da parte do perito, uma abordagem específica e um modo de pensar próprio: as crianças, os idosos, as pessoas com handicaps sensoriais e aquelas com handicaps mentais.

No caso das crianças, o balanço definitivo da necessidade de terceira pessoa só pode por vezes ser efectuado no fim da puberdade, no fim do período de crescimento.

Já no caso dos idosos, é frequente que sequelas físicas objectivamente moderadas possam provocar uma redução de autonomia que se afigure desproporcionada para o perito não familiarizado com a patologia geriátrica.
Quanto às pessoas com handicaps sensoriais, há que ter em conta que o mundo das pessoas invisuais e surdas é difícil de apreender por aqueles cujos sistemas sensoriais estão intactos, sendo aqui a terceira pessoa apenas para uma intervenção limitada, pontual, mas absolutamente indispensável, pelo que deve o estudo pericial ser simultaneamente muito atento e imaginativo.

Finalmente, as pessoas com défices mentais, além de outros eventuais handicaps, podem estar incapazes para reger a sua própria pessoa e bens, além de poderem constituir perigo para si mesmas ou para os outros; nestes casos pode ser necessário um acompanhamento constante e mesmo medidas de protecção jurídica apropriadas.

Todos estes casos colocam sempre problemas muito dificeis na avaliação do dano corporal e a atribuição de terceira pessoa é, manifestamente, um deles.

\section{CONCLUSÃO}

A avaliação das vítimas com handicap grave e, portanto, com autonomia reduzida ou mesmo sem autonomia, constitui um acto pericial que supõe, para além da competência médico-legal, a escuta particularmente atenta, a observação crítica (preferencialmente no local), mas também conhecimentos sobre psicologia, serviço social, medicina física e de reabilitação, ergonomia, entre outros, que extravasam os conhecimentos exclusivamente médicos, pelo que a perícia deverá ser sempre multidisciplinar.

Trata-se de uma avaliação complexa que exige formação particular dos profissionais que nela intervêm, bem como o tempo necessário para executar bem uma missão que sai manifestamente da rotina pericial.

Ainda que o modo de indemnização não seja um problema médico, uma perícia, por mais bem 
feita que seja, não alcançará os seus objectivos se o modo de indemnização não se adequar, também, a esses objectivos - a melhor reintegração possível da vítima em termos de autonomia e qualidade de vida.

Assim, afigura-se do ponto de vista médico-pericial, que a indemnização através de renda seria mais justa e mais adequada a poder ser adaptada à realidade de cada fase da vida da vítima. Ainda assim, a indemnização ideal seria mista; em capital, para fazer face às necessidades imediatas, in natura, para fornecer à vítima as competências tecnológicas necessárias, e em renda, para garantir o futuro com possibilidade de ajustamento às reais necessidades.
Nesta ordem de pensamento, parece lógico que no caso dos handicaps graves não sejam nunca as conclusões periciais definitivas, procurando cobrir apenas períodos não superiores a cinco anos.

Se tudo o que aqui foi preconizado em relação às modalidades de avaliação e reparação puder um dia ser concretizado, estamos certos que o processo de reintegração destas pessoas será mais curto e mais efectivo, o que irá reduzir as despesas do período de incapacidade temporária e futuras, beneficiando todos os intervenientes directos neste processo (o sinistrado, a família, a companhia de seguros) e a sociedade em geral.

\section{BIBLIOGRAFIA}

DEMOLIN, B.; CHAMPAUD, E.; PIGANIOL, G. - La tierce personne. Revue Française du Dommage Corporel. Paris: J. B. Baillière éditeur. Tome 16, n. ${ }^{\circ} 4$ (1994), p. 615-633.

FOUGEYROLLAS P. - La revision de la Classification des Handicaps: le point sur les travaux du Québec. In: Actes du Colloque CTNERHI "Classification Internationale des Handicaps: Du Concept à l'Application". Paris: Diffusion PUF, 1988. HAMONET C. - Évaluation tridimensionnelle en réadaptation médicale; Handiscope-Handicapomètre - Index de Créteil, J.Réadapt.Méd. vol. 11, n. ${ }^{\circ} 3$ (1991), p.175-182.

HAMONET C, MAGALHÃES, T. - Système d'Identiication et de Mesure dês Handicaps. Paris: ESKA, 2001.

MAGALHÃES, T. - Avaliação Tridimensional do Dano Corporal: Lesão, Função e Situação. Sua Aplicação Médico-Legal. Coimbra: Livraria Almedina, 1998.

NAGI SZ. Some conceptual issues in disability and reabilitation, Sociology and reabilitation. Ohio: Ohio State University Press, 1965.

PAPELARD, ALAIN; ROGIER, ANTOINE- L'avis médical et l'expertise. Revue francaise du dommage corporel. Paris: J. B. Baillière éditeur. Tome 19, n. ${ }^{\circ} 2$ (1993), p. 129-133.

PHILOPOULOS, Dimitri; HAMONET, Claude - Méthodologie de l'estimation du besoin en tierce personne en pratica médico-légale. Gazette du Palais. Vol. 126, n. ${ }^{0} 193$ (2006), p 16-22.

ROGIER, A. - L'avis médical et l'expertise. Revue francaise du dommage corporel. Paris: J. B. Baillière éditeur. Tome 19. n. ${ }^{\circ} 2$ (1993), p. $123-128$.

ROUSSEAU, Claude - Aides humaines et tierce personne. Revue Française du Dommage Corporel, Paris: J. B. Baillière éditeur. Tome 20, n. ${ }^{\circ} 2$ (1994), p.3-4.

WOOD PHN. - Comment mesurer les conséquences de la maladie: la classification internationale des infirmités, incapacités et handicaps, Chronique OMS, 1980. 


\section{Biblioteca Seguros}

Publicação da Caixa Seguros

Co-edição Caixa Seguros e Imprensa da Universidade de Coimbra

\section{Título}

Aspectos práticos da avaliação do dano corporal em Direito Civil

\section{Coordenação}

Duarte Nuno Vieira e José Alvarez Quintero

\section{Tradução}

Sónia Almeida

Design

Liquid Design

Impressão

SerSilito-Empresa Gráfica, Lda.

ISBN 978-989-8074-31-7

Depósito Legal 279157/08

Julho 2008 

CAIXA SEGUROS, SGPS, S.A.

Grupo Caixa Geral de Depósitos 